\title{
American Pediatric Society's 2009 John Howland Award Acceptance Lecture: Lessons Learned From Time
}

\author{
JEROLD F. LUCEY \\ Department of Pediatrics, University of Vermont College of Medicine, Burlington, Vermont 05405
}

$\mathrm{I}_{\mathrm{i}}$ am deeply honored to receive this award. In looking over the list of previous awardees, I realized I have had the privilege to have had seven, as my mentors and teachers. Each one had an important role in my education.

Dr. L. Emmett Holt Jr. (1966 Howland Awardee) was a quiet, soft-spoken, and wise person, who rarely gave advice. I was, therefore, surprised when, in 1952, I told him I intended to specialize in the care of premature infants, and his comments were, "That's an odd choice. You can't make a living doing that." I later learned that he gave similar advice to Bill Tooley and Stan James when they were in their residency at Bellevue Hospital. I ended up following my heart and not his advice.

Dr. Saul Krugeman (1981 Howland Awardee) was a superb teacher, who was loved and admired by students and house staff. He was a true hero, under attack by the press for his hepatitis study being carried out on retarded children at Willowbrook. We knew he was suffering from the vicious attacks, but he never let it interfere with his teaching.

Henry Barnett (1984 Howland Awardee) was my mentor during a 2-mo elective period I took at the New York Hospital. This was my first exposure to research on premature infants. He was kind and gentle and carefully explained his research project to parents and house staff.

Rustin McIntosh (1961 Howland Awardee) was a Chairman of the department at Babies Hospital, Columbia Presbyterian Medical Center. I was a senior resident and met with him for 1 hour a day for over a year. It was a great learning experience. He had the ability to ask pointed questions in a nonintimidating way. I am forever grateful to him for suggesting I should consider going to Vermont to work for Jim McKay, a former resident at Babies Hospital, then the only full-time pediatrician at the University of Vermont College of Medicine.

John Caffey (1965 Howland Awardee) was my idol. He was a real curmudgeon. I was intimidated by him. He was the father of pediatric radiology. He would not read an x-ray request unless you wrote out a legible brief history. I was allowed to watch him read x-rays for about an hour each day, and I lost my fear of him when I realized he had a heart of gold and was a true scholar.

Received July 10, 2009; accepted August 25, 2009.

Correspondence: Jerold F. Lucey, M.D., F.A.A.P., Department of Pediatrics, University of Vermont College of Medicine, 89 Beaumont Avenue, Given D201, Burlington, VT 05405; e-mail: jerold.lucey@uvm.edu

Presented at the 2009 Annual Meeting of the Pediatric Academic Societies, Baltimore, MD.
Richard Day (1986 Howland Awardee) introduced me to the whole new world of randomized trials. He and Bill Silverman were introducing randomized trials to pediatrics. It is hard to imagine that in the early 1950s, such "trials" were not accepted by many teaching pediatricians. The attitude was that it is not fair to treat a baby one way and deny the same therapy to another infant. A seminal event in my life occurred at that time, which had a profound effect on my life years later. At that point in my career, I had worked in three premature center units in New York City (Bellevue, NY Hospital and Babies Hospital). Each center quietly considered itself "the best" by comparing crude mortality figures. I presented my findings at an informal teaching conference attended by Drs. McIntosh, Day, and Silverman. My professors studied my findings and pointed out that I used noncomparable figures and flawed data, which was impossible to interpret and could not be used. I felt pretty stupid, but the admission of ignorance is the beginning of learning. Nearly $30 \mathrm{y}$ later, I returned to this idea of comparing neonatal units' mortality and morbidity, but this time, I had Jeff Horbar and Roger Soll, who did know how to do it, working with me and the Vermont Oxford Network was born.

Clement A. Smith (1976 Howland Awardee): I heard Clem speak at Babies Hospital, read his book, Physiology of the Newborn Infant, and fell in love with the man and his subject. I spent 2 years at the Boston Lying-in Hospital, which at the time was an international center for future neonatologists.

These were my first formal "teachers." They each had a profound influence on my life but in looking back nearly $80 \mathrm{y}$, I realized I had been destined for a medical career at the early age of about $6 \mathrm{y}$ when I was playing doctor among several children who were playing.

At the age of $12 \mathrm{y}$, I lived with my uncle, a family doctor, for a year. He went to work at 7 a.m. and usually returned home at 10 p.m.! He was beloved and admired. I realized I wanted to be a doctor, but not the kind of doctor he was.

My final course was set in college. I fell under the spell of my zoology professor. He took me to the Mt. Desert Island Biology Laboratory. Those two summers, I did my first experiments and solved two problems: 1) how to collect blood and urine from a fish and 2) how to force feed baby seals, all alone and without books, etc. For the first time, I experienced the thrill of discovering something all by myself. I am to this day probably the only person to know the insulin clearance rate of the sculpin (a fish).

In Boston, I worked with a team of six other neonatologists doing a study of the pressure it takes for an infant's first 
breath. I began to realize that in Vermont, I would be the only person in a two-man department doing research. My chairman, Jim McKay, was an ideal chairman and mentor. His desires and my goals were to do research, teach full time every day, Saturday and Sunday included, travel, and get our department well known.

My first overseas travel was to Portugal for an international meeting. I met a young man from Chile, Dr. Mario Ferreiro, who wanted to come to Vermont. He did not mind winter or the small size of our department. We picked a project, which could be carried out in Vermont. For 10 y, phototherapy had been used in other countries, but not in England (where its use was first described) or in the United States. I had criticized the original study, because it was small and uncontrolled. I did not think that it would work. We decided to do a randomized control trial. It took 2 years (Fig. 1). I spent the next $10 \mathrm{y}$ defending its use. During this time, Jim McKay, my mentor introduced me to the AAP, and I ended up working on the fetus and Newborn Committee for 6 years. We accomplished a great deal, starting regionalization and updated recommendations on the use of oxygen. I will always remember the audience reactions when, at a special AAP meeting, I announced that the committee was recommending arterial $\mathrm{Po}_{2}$ measurements as essential. The audience booed loudly - a first in my career.

I spent 6 years on the editorial board of Pediatrics before becoming editor in 1974. The appointment was for 1 year. I never expected to last 34 y. I loved the "job." I am proud of the journals growth over those $34 \mathrm{y}$ :

- Circulation 1972 (12,000)-2009 (66,000)

- Foreign editions: Italy, Spain, China, Portugal, Turkey, and Poland

- High impact factor

- Electronic edition with more than 16,000,000 visits per year

- Among the top 100 journals in citations

Jeff Horbar joined the department 33 y ago. Roger Soll joined us 26 y ago. They enabled me to revive my old idea of

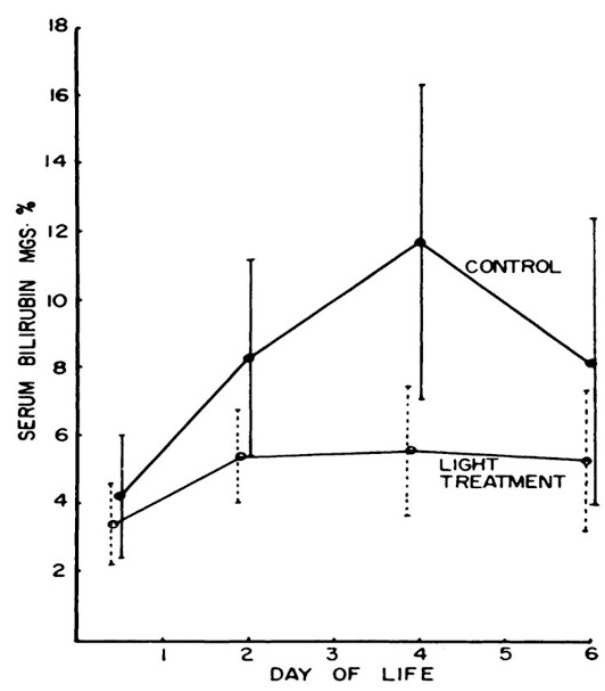

Figure 1. Prevention of hyperbilirubinemia of prematurity by phototherapy. Reprinted from Lucey J.F. et al. Pediatrics 1968;41:1047-1054. Copyright (C) 1968 The American Academy of Pediatrics, with permission.
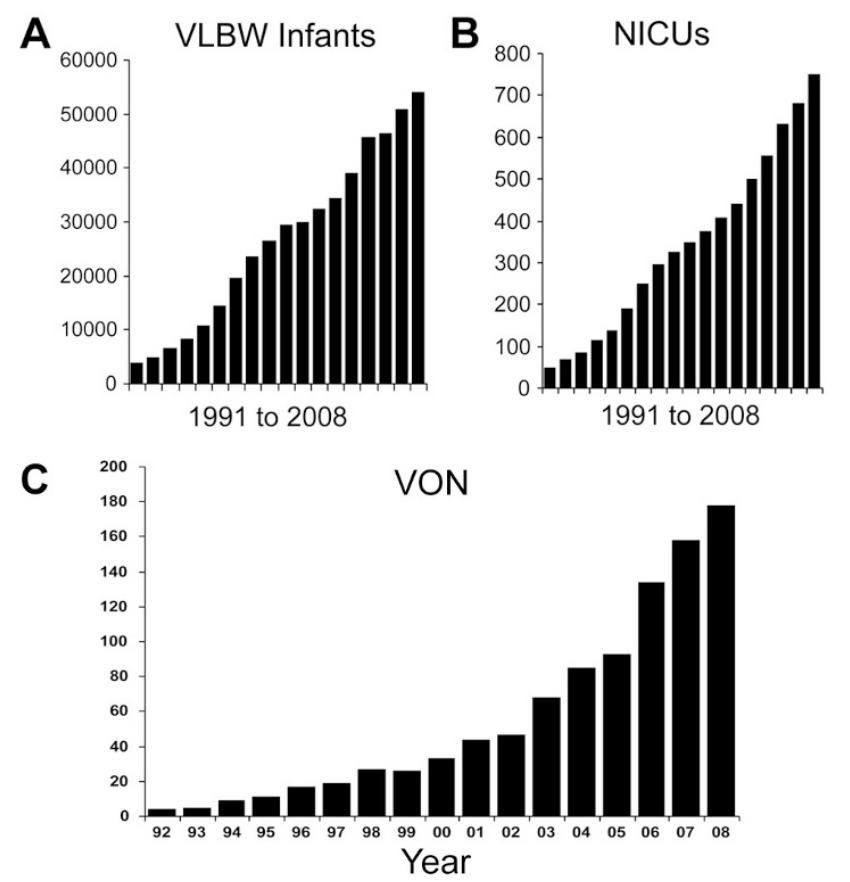

Figure 2. Growth of the Vermont Oxford Network from 1991 to 2008 ( $A$ and $B$ ). In 2008 , more than 50,000 VLBW babies were treated at 750 NICUs world wide. $C$, Vermont Oxford Network is comprised of 179 NICUs in 24 countries. International members include: Austria, Belgium, Brazil, Canada, Chile, China, Czech Republic, Finland, Germany, Ireland, Italy, Kuwait, Malaysia, Northern Ireland, Portugal, Saudi Arabia, Singapore, Slovenia, South Africa, Spain, Switzerland, Turkey, The United Arab Emirates, and United Kingdom.

Table 1. Recommendations for neonatology

Networks-cluster trials

Faster, larger RCTs

Longer follow-up, $8+\mathrm{y}$

Brain care

comparing mortality and morbidity rates of neonatal intensive care units-the Vermont-Oxford Network's NICUs. We started with 34 NICUs in 1989 and now in May, 2009, have over 830 in 26 countries (Fig. 2)!

At this point, the Howland Awardee usually makes a few recommendations about the future of his specialty (Table 1). We need faster and larger randomized control trials. Cluster trials are probably the way to achieve this goal. It is absolutely essential that longer follow-up studies be required. The field of the future will be in improving brain care, probably involving the development of very specialized centers.

In closing, for the younger physicians in the audience, I would like to pass on some advice, the lessons I have learned over time.

- Find Something you love to do (It wont seem like work!).

- Find a beautiful place to live and somebody to share it with you.

- Find somebody to pay you.

- Stay there!!

It has worked for me and it should work for you! 